\title{
Contextualiser les théories du jeu de Johan Huizinga et Roger Caillois
}

Contextualizing the Theories of Game and Play of Johan Huizinga and Roger Caillois

\section{Laurent Di Filippo}

\section{(2) OpenEdition}

\section{Journals}

Édition électronique

URL : http://journals.openedition.org/questionsdecommunication/9044

DOI : 10.4000/questionsdecommunication. 9044

ISSN : 2259-8901

\section{Éditeur}

Presses universitaires de Lorraine

\section{Édition imprimée}

Date de publication : 31 août 2014

Pagination : 281-308

ISBN : 978-2-8143-0209-9

ISSN : 1633-5961

\section{Référence électronique}

Laurent Di Filippo, « Contextualiser les théories du jeu de Johan Huizinga et Roger Caillois », Questions de communication [En ligne], 25 | 2014, mis en ligne le 01 juillet 2016, consulté le 10 décembre 2020 URL : http://journals.openedition.org/questionsdecommunication/9044; DOI : https://doi.org/ 10.4000/questionsdecommunication.9044 
LAURENT DI FILIPPO

Centre de recherche sur les médiations

Université de Lorraine

F-57000

laurent@di-filippo.fr

\title{
CONTEXTUALISER LES THÉORIES DU JEU DE JOHAN HUIZINGA ET ROGER CAILLOIS
}

\begin{abstract}
Résumé. - Les réflexions de deux des théoriciens du jeu parmi les plus importants, Johan Huizinga et Roger Caillois, font régulièrement l'objet de citations et de discussions dans des recherches diverses. Cependant, dans les études sur le jeu, force est de constater que peu de chercheurs se référant à leurs travaux s'attachent à les replacer dans leurs contextes sociohistoriques ou dans l'œuvre globale de leurs auteurs. L'article vise à combler ce vide et montre que les théories des deux hommes impliquent une vision du monde qui leur est propre et ne peuvent par conséquent pas être reprises sans interroger leurs fondements, leurs implications ainsi que leurs enjeux.
\end{abstract}

Mots clés. - Johan Huizinga, Roger Caillois, jeu, théorie, culture, civilisation, sacré. 
$\mathrm{D}$ epuis quelques décennies, l'importance prise par les industries du jeu et leur place de plus en plus visible dans les pratiques culturelles, notamment à la suite de l'essor des jeux vidéo, entraînent une multiplication des travaux scientifiques portant sur ces thèmes'. Sous le terme « jeu » se retrouvent des phénomènes variés auxquels de nombreux auteurs ont tenté de donner des définitions. Comme dans tout travail de recherche, ces derniers font alors appel aux théories de leurs prédécesseurs qui ont abordé des thèmes similaires. Développées dans leurs ouvrages majeurs respectifs, Homo Ludens (1938) et Les jeux et les hommes (1958b), les théories de Johan Huizinga et de Roger Caillois font office de « passage obligé » pour les chercheurs sur le jeu. Cependant, force est de constater que si beaucoup, reprenant leurs théories, se sont attachés à les présenter afin de les critiquer, très peu ont cherché à les replacer dans leurs contextes sociohistoriques ou dans les œuvres globales de leurs auteurs. On trouve un exemple frappant de ce type dans le livre de Jesper Juul, HalfReal (2005 : 30), qui juxtapose et compare plusieurs définitions du jeu sans jamais les recontextualiser et qui, à partir de cela, propose ce qu'il appelle un « modèle classique du jeu » (« classic game model »), capable, selon lui, d'expliquer au moins 5000 ans de jeu dans l'histoire de l'humanité ... Face à cette proposition, il est possible d'objecter que « les jeux accompagnent les évolutions du social et celles-ci en retour modifient la nature du jeu et de ce qui s'y joue » (Schmoll, 20 I I : I0). Ceci n'est d'ailleurs pas sans rappeler les propos de Jacques Henriot (1989:26-27) disant, au sujet du jeu, qu'« il n'est pas évident qu'il y ait "quelque chose" qui corresponde à ce que conçoivent les hommes qui appartiennent à des sociétés différentes, qui vivent à des époques différentes, qui parlent des langues différentes ». Pour aborder ces différences, il semble nécessaire de mieux comprendre les multiples enjeux et implications des définitions et des théories du jeu, à commencer par celles de Johan Huizinga et de Roger Caillois.

La nécessité de ce travail est apparue après avoir abordé les liens entre le jeu et le sacré dans un article écrit en collaboration avec Patrick Schmoll (2013). Nous constations alors que les deux auteurs établissaient un rapport entre ces deux notions et se situaient ainsi dans la continuité des travaux sur le sacré de l'école française de sociologie. C'est d'ailleurs sur ce rapprochement que porteront les premières critiques de Roger Caillois (1946) à l'encontre des théories de l'auteur néerlandais. Puis, il fera évoluer ses propres théories à la suite des échanges qu'il aura au milieu des années 50 avec Claude Lévi-Strauss. II convient alors d'interroger la manière dont ces deux pensées se sont construites, leurs sous-entendus, leurs implications en termes de vision du monde, les enjeux liés à leur reprise ou la manière d'en faire une critique pertinente, pour qui veut saisir correctement la portée de ces travaux, les réutiliser ou les remettre en question. Ce questionnement participe de l'attitude réflexive que tout chercheur se doit d'adopter face aux théories qu'il utilise (Di Filippo, François, Michel, 2013 : I2-13).Aborder les fondements de ces relations entre

' Nous tenons à remercier les deux experts pour leur relecture attentive, la pertinence de leurs conseils ainsi que pour les références complémentaires qui ont permis de préciser le travail effectué dans cet article. 
jeu et sacré permettra aussi de se demander si, dans ce cadre précis, on retrouve les caractères du sacré en dehors de la sphère religieuse (Boutaud, Dufour, 2013 : 8), en revenant aux définitions données par les chercheurs qui ont fondé la notion de sacré et comment celle-ci a influencé les définitions du jeu des deux auteurs présentés.

Leurs travaux seront traités de manière chronologique, en commençant par les textes de Johan Huizinga, afin de montrer que c'est, entre autres ressources, à partir de ceux-ci que Roger Caillois construisit les siens. L'objectif de la contribution est donc avant tout d'offrir une meilleure compréhension des fondements des théories des deux hommes et non de proposer une nouvelle théorie du jeu à partir de leurs travaux. Comme Camille Tarot (2003 : 270), on peut se poser la question de savoir si « des faits importants, des acquis sous-estimés attendent dans les échecs de grands esprits », car sans doute « il n'y a pas que des échecs dans leurs voies ».

\section{Définitions et influences}

Pour Johan Huizinga (1938:5 I), le jeu « est une action ou une activité volontaire, accomplie dans certaines limites fixées de temps et de lieu, suivant une règle librement consentie mais complètement impérieuse, pourvue d'une fin en soi, accompagnée d'un sentiment de tension et de joie, et d'une conscience d' "être autrement" que dans la "vie courante" ». À cette définition, Roger Caillois (1958b : 43) rajoute qu'elle est « improductive » et que son issue est « incertaine ». Ces deux définitions ont pour intérêt de définir le jeu comme une activité sociale et orientent son étude vers des problématiques anthropologiques, sociologiques, voire historiques, traitant de l'organisation de l'espace social. Il s'agit donc moins d'étudier les jeux en tant qu'objet matériel (ce qui rapprocherait alors le terme de celui de jouets), que de considérer leur rôle dans la constitution des sociétés. Thierry Wendling (2000 : 27) note que Johan « Huizinga avance sans crier gare l'ébauche d'une théorie générale de la culture », qu'il évoque plus tard comme une « anthropologie générale » (Wendling, à paraitre : 215). En plus de sa définition, Roger Caillois (1958b : 45-92) a proposé une typologie des jeux définissant quatre « catégories fondamentales »- l'alea, l'agon, l'ilinx et la mimicry - et deux principes - ludus et paidia - servant à catégoriser les attitudes mentales des individus propres à différents jeux. Ces théories permettent de réfléchir au rapport établi entre la notion de jeu et celles de culture ou de société, à condition de bien comprendre le sens que ces auteurs attachent à ces notions.

Leurs théories et définitions du jeu ont irrigué de nombreux travaux traitant de cet objet dans son aspect global (Henriot, 1989 : I7| - I75 ; Brougère, 2005 : 40), de jeux plus particuliers, tels le jeu d'échecs (Wendling, 2002 : 34-44), les jeux de rôle (Caira, 2007 : 206-2 I0) ou les jeux vidéo (Juul, 2005 : 30 ;Taylor, 2006 : 88). Ces derniers servent aussi à interroger des thématiques plus générales comme le rapport que le jeu entretient à la culture (Genvo, 2009 : 9, I I I ; Mäyrä, 2008 : 20-2 I), les oppositions entre jeu et sérieux - importantes, notamment, chez Johan Huizinga (Bogost, 2007 : 57-55) - ou entre narratologie et ludologie dans l'étude 
des jeux vidéo que Gonzalo Frasca (2003) a discutées à partir des catégories de ludus et de paidia. Les ouvrages des deux hommes ont aussi engendré des discussions en dehors de leurs disciplines d'origine. Pour Roger Caillois, citons par exemple Ruth Amossy (1991 : 137-138) qui évoque sa définition du jeu et la mimicry dans le cadre d'études littéraires, et François Jost (2006 : 184) dans ses études sur la télévision. Pour sa part, Johan Huizinga a suscité les réactions de spécialistes du droit en Italie (Andrini, |99|). S'ils ne font pas toujours I'unanimité, loin de là, ces travaux provoquent des discussions.

Comme nous le voyons, de nombreux chercheurs s'inspirent des travaux des deux auteurs, s'attachant parfois à un point particulier de leurs démonstrations, et remettent en question plusieurs des aspects de leurs définitions. Parmi les critiques les plus fréquentes, on retrouve l'idée selon laquelle le jeu n'est pas totalement séparé de la vie courante, ou encore une remise en question des combinaisons possibles dans la typologie de Roger Caillois. Cependant, ces critiques ne proposent pas de replacer les théories du jeu de ces auteurs, ainsi que les définitions de cette notion qui en découlent, dans leurs contextes historiques, ni dans leurs œuvres globales. Ce défaut est particulièrement présent chez des auteurs contemporains des games studies. Néanmoins, le présent travail doit aider à définir l'« horizon de pertinence »(Leleu-Merviel, 2010 : 174) des travaux de Johan Huizinga et de Roger Caillois, c'est-à-dire aider à prendre la mesure de leur validité afin de déterminer leurs apports possibles dans les études contemporaines sur le jeu.

\section{Johan Huizinga, historien de la culture}

Historien néerlandais, Johan Huizinga naît en |872. I| vit la Première Guerre mondiale ainsi que les nombreux changements que connaît la société durant l'entre-deux-guerres, comme le développement des moyens de communication dont il évoquera les effets dans son ouvrage Incertitudes (Huizinga, 1935 : 77-79). Il observe également la montée du fascisme italien et du nazisme, en Allemagne. Ce dernier point est important car il explique un certain nombre d'orientations prises dans son ouvrage principal sur le jeu, traduit sous le titre Homo Ludens. Essai sur la fonction sociale du jeu, qui parait dans sa langue originale en 1938. En effet, la clé de lecture de l'ouvrage repose dans le dernier chapitre, intitulé « L'élément ludique de la culture contemporaine » (Huizinga, 1938 : 268-292). Thierry Wendling (2000:27) précise que l'ouvrage fut « rédigé, en partie, sous la pression des événements » et qu'il « ne se comprend pas indépendamment du contexte de sa parution » (ibid. : 35). Il faut ainsi le lire comme « la contribution d'un grand intellectuel à la lutte contre le nazisme » (Wendling, à paraître : 213).

Avant cela, Johan Huizinga avait déjà publié plusieurs textes dans lesquels il mettait en avant les valeurs qu'il accordait à la culture et à l'histoire. Dans un de ses premiers ouvrages majeurs, L'automne du Moyen Âge (1919), il évoque les valeurs de cette période, telle la chevalerie, ou les rêves d'héroïsme et d'amour. Un autre ouvrage 
important, dont la publication précède de peu celle d'Homo Ludens, est traduit sous le titre Incertitudes. Essai de diagnostic du mal dont souffre notre temps (1935) qui, en version originale, fait référence à la souffrance mentale et spirituelle (« geestelijk lijden ») de son époque. L'auteur y reviendra dans À l'aube de la paix. Étude sur les chances de rétablissement de notre civilisation (1945), intitulé en néerlandais Geschonden wereld (1945:4) soit, littéralement, « monde abimé », mais le terme peut aussi renvoyer à l'idée de monde dégradé, violé, profané2. Johan Huizinga s'intéresse donc à l'évolution des sociétés et aux effets de ces changements au cours du temps. Ainsi pouvons-nous comprendre ses textes comme ceux d'un observateur critique des transformations culturelles qui s'opèrent dans la société.

\section{Période de l'entre-deux-guerres}

Le contexte historique durant lequel Johan Huizinga (1938) écrit Homo Ludens est marqué par les développements techniques, la crise économique et, on l'a signalée, la montée du fascisme italien et du nazisme, plusieurs phénomènes qui vont grandement orienter ses réflexions dans une optique de contestation. Son attitude envers le régime nazi lui vaudra d'être enfermé durant trois mois dans un camp d'otages puis exilé en province. II faut garder cela à l'esprit lorsque Johan Huizinga (1938: 288) évoque, à la fin de son livre, l'idée d'une certaine perte de valeurs associée aux changements de société : «Peu à peu, nous en sommes arrivés à la conviction que la culture est fondée sur le jeu noble, et qu'elle ne peut manquer de teneur ludique, si elle veut déployer sa qualité suprême de style et de dignité. Nulle part, l'observance des règles établies n'est aussi indispensable que dans les relations entre peuples et États. Si ces règles sont violées, la société tombe alors dans la barbarie et le chaos ». Comme le montre cette citation, l'auteur associe la culture à un certain nombre de valeurs morales également présentes dans le jeu qu'il qualifie de « noble ». Ainsi semble-t-il définir un idéal pour la culture dans les conventions ou les normes qui, comme les règles du jeu, doivent être respectées, car elles définissent les conditions du respect mutuel entre les participants. Sans cela, les sociétés perdraient ce qui constitue leur plus grande qualité.

Pour mieux comprendre cela, il faut se tourner vers son essai précédent, Incertitudes (1935). Les titres des chapitres sont évocateurs. Voici quelques exemples : « Aspects problématiques du progrès » (ibid. : 55-59), « Affaiblissement général du jugement » (ibid. : 7/-83), « Déclin du besoin critique » (ibid. : 85-98), « Renoncement à l'idéal de connaissance » (ibid. : | 05- | | 0), « Déclin des normes morales » (ibid. : | 133-|46), etc. Ces titres évoquent un retour en arrière, ou une régression par rapport à des qualités acquises avec le temps, ainsi qu'une forme d'abandon des valeurs que l'auteur considère comme importantes pour définir ce

\footnotetext{
2 Dictionnaire en ligne Van Dale. Accès : http://www.vandale.nl/opzoeken?pattern=Geschonden\&lan g=nf. Consulté le 20/05//3.
} 
qui fait le mérite d'une culture. II consacre également un chapitre au puérilisme ${ }^{3}$ (ibid. : 175- 187). II « appelle puérilisme l'attitude d'une société dont la conduite ne correspond pas au degré de discernement et de maturité auquel elle est censée être parvenue, une société qui, au lieu de préparer l'adolescent à passer à l'âge viril, adapte sa propre conduite à celle de l'enfance » (ibid. : 175). Johan Huizinga utilise une métaphore anthropomorphique pour appuyer sa vision du progrès des sociétés vers un stade de raison. Le puérilisme est une forme d'inadaptation des comportements effectifs à ceux attendus qui créé une dissonance entre une projection idéale de ce que la société doit être selon l'auteur et ce qu'il observe. Tour à tour, Johan Huizinga y joint les intrigues politiques, les changements de nom de villes, les parades et marches au pas qui rassemblent des milliers d'hommes et qui suggèrent une « apparente grandeur et force trompeuse » (ibid. : | 76), rajoutant que « le salut fasciste est proche du puérilisme général » (ibid. : 177). Quant aux États-Unis, ils sont le pays le plus puéril, mais cela est pardonnable car c'est aussi un pays plus jeune et à l'esprit plus « gamin » (ibid.) ; il est donc simplement plus naiif que les pays européens. Cette image exprime l'idée selon laquelle les sociétés acquièrent une forme d'expérience avec le temps et ce presque indépendamment de leurs membres. Ensuite, les exemples se multiplient de la même manière tout au long du chapitre jusqu'à dénoncer la devise allemande « Blut und Boden (sang et sol) » (ibid. : | 85) comme n'étant rien d'autre qu'un slogan, c'est-à-dire qu'elle « appartient au domaine de la réclame » et, par conséquent, n'est pas sérieuse.

Pour l'auteur néerlandais, le danger survient lorsque le puérilisme entraine une attitude sérieuse. Pour résumer, « la confusion du jeu et du sérieux, qui est au fond de tout ce qu'ici nous entendons par puérilisme, est de tous les signes du mal dont souffre la vie contemporaine, indéniablement le plus important » (ibid. : | 86). Tout ce que l'auteur condamne dans le reste de l'ouvrage conduit au puérilisme qu'il dénonce, que ce soit les développements techniques pour lesquels l'homme n'est pas prêt ou la baisse des exigences concernant le regard critique qu'il est nécessaire de porter sur le monde. Comme le remarque Thierry Wendling (2000: 36), la fonction créative que Johan Huizinga accorde à la culture par son aspect ludique se perd dans le puérilisme. S'appuyant sur les thèses d'Oswald Spengler, dont l'ouvrage Le déclin de l'Occident (1918-1922) était déjà cité comme étant un « signal d'alarme pour d'innombrables humains » (Huizinga, 1935: 19), il « fait le départ entre d'un côté une culture jouée et noble et de l'autre un puérilisme dont il perçoit avec acuité le danger extrême » (Wendling, 2000 : 36). Chez Johan Huizinga, on constate une vision particulière du progrès qui a pour objectif de conduire à une société meilleure parce que ses membres auraient une conscience plus grande de ce qui constitue les bonnes attitudes à adopter, ce qui pourrait être comparé à une forme de sagesse. D'ailleurs, la confusion des attitudes liées au jeu et au sérieux est considérée comme le «mal » spirituel qu'évoque le titre de l'ouvrage. On observe alors un jugement moral dans l'analyse du changement et de l'évolution culturelle et sociale de l'auteur.

\footnotetext{
${ }^{3}$ Le terme utilisé dans ce chapitre dans la version originale est « puerilisme », sans accent.
} 
C'est aussi dans ce chapitre que l'on trouve des réflexions sur le jeu qui préparent celles d'Homo Ludens : « Dans ses phases primitives, la vie sociale se passe en grande partie en jeux. C'est une trêve temporaire des activités humaines habituelles se passant en divertissements, d'après des règles librement consenties et sous une forme fixe et déterminée » (Huizinga, 1935 : 180). Caractère séparé de la vie courante, réglé, librement consenti et dont la forme et les limites de temps et d'espace sont déterminées à l'avance, tels sont les traits principaux de la définition du jeu dans Homo Ludens. Mais, selon Johan Huizinga, le plus important est que « ce qui caractérise le plus essentiellement tout jeu véritable, c'est qu'à un moment donné, il cesse. Les spectateurs retournent chez eux, les acteurs déposent leurs masques, la représentation est finie. C'est ici qu'apparaît le défaut de notre temps. Dans bien des cas, le jeu, aujourd'hui, ne finit jamais. Ce n'est donc pas un jeu véritable. II y a là une grave contamination entre le jeu et le sérieux : les deux sphères se sont mêlées » (ibid. : |8|). Néanmoins, l'historien néerlandais suggère que, en y regardant de plus près, la confusion entre jeu et sérieux « a toujours existé dans une certaine mesure » (ibid.), surtout dans la psychologie animale, mais qu'on doit à la société occidentale d'avoir entremêlé les deux sphères à l'extrême. Les conséquences sont l'incapacité à reconnaître ce qui convient et ce qui est déplacé, l'absence de dignité personnelle, de respect d'autrui et de ses opinions qui aboutit à une forme d'égocentrisme (ibid. : 182). Cela renvoie à la dimension morale de l'analyse de Johan Huizinga.

À la suite de cela, il fallait à l'auteur écrire un ouvrage qui permettrait de lutter contre ces dérives, contre cette contamination, qui n'est pas sans rappeler celle entre le sacré et le profane (voir infra), avec les moyens à sa disposition, c'est-à-dire l'érudition du professeur et l'écriture. Son âge avancé au début de la guerre et la position de son pays ne lui laissant, sans doute, que peu d'alternatives. C'est dans ce contexte qu'Homo Ludens voit le jour. Dans cet ouvrage, Johan Huizinga (1938 : 25) revient sur les difficultés que pose la distinction entre jeu et sérieux, qui, selon lui, reste « flottante ». Sa distinction sera moins stricte puisqu'il dira que « l'attitude ludique authentique et spontanée peut être celle du profond sérieux. Le joueur peut s'abandonner au jeu de tout son être » (ibid. : 41 ). On voit la difficulté que pose à l'auteur le vocabulaire employé, sans doute due à la polysémie des termes. Étudiant d'un point de vue philologique différentes acceptions des notions de jeu et de sérieux dans plusieurs langues, il arrive à la conclusion que les termes désignant le sérieux « représentent une tentative secondaire de la langue en vue d'exprimer la notion générale antithétique de la notion générale du jeu » (ibid. : 73). Là où le jeu est une notion en soi, qui ne se limite pas à désigner le non-sérieux, l'idée de sérieux, quant à elle, ne se comprend que dans son opposition avec le jeu. Cela fait de la notion « jeu » une notion première par rapport à celle de « sérieux ». Ce que Johan Huizinga justifie ainsi : « Le sérieux tend à exclure le jeu, tandis que le jeu peut fort bien englober le sérieux » (ibid.). C'est l'opposition entre jeu et « vie courante » qui deviendra primordiale dans son propos, cette dernière pouvant à tout moment faire irruption et rompre le jeu (ibid. : 42). Cette dualité sera au fondement de la théorie de l'émergence de la culture qu'il développera et qu'il convient d'éclairer. 


\section{Jeu et culture}

Johan Huizinga (1938: 1 12) écrit que « la culture ne naît pas en tant que jeu, ni du jeu mais dans le jeu ». Pour lui, notamment dans son aspect agonal de compétition, le jeu est une des composantes à la base de toute culture. Cependant, le terme « culture » pose des problèmes de définition, car son usage varie dans le temps, dans les espaces géographique et social, comme l'a montré Denys Cuche (1996). Aujourd'hui, il est donc difficile pour un chercheur de reprendre cette proposition à son compte sans interroger la définition que donne Johan Huizinga au terme « culture ». Bien entendu, la traduction du néerlandais au français pose un premier problème. De plus, dans Homo Ludens, à aucun moment cette question n'est posée clairement de cette façon - ce que note aussi Thierry Wendling (2000 : 29). Heureusement, ces deux obstacles peuvent être surmontés, car c'est l'un des sujets que l'auteur traite dans deux autres ouvrages, Incertitudes (1935) publié avant Homo Ludens, et À l'aube de la paix ( 1945), qu'il écrit juste après. L'auteur y détaille ce qu'il entend par culture et civilisation, deux termes dont les sens se recouvrent dans son propos. II est donc possible de comprendre à quoi ces termes renvoient sous sa plume. Sa pensée restant cohérente entre les deux volumes, on peut en déduire qu'il n'a pas eu une vision différente lorsqu'il écrivait son ouvrage sur le jeu, et plusieurs points s'y trouvant vont le confirmer.

Dans le premier de ces ouvrages, Johan Huizinga (1935:41-53) consacre un chapitre aux « conditions essentielles de la culture ». Pour lui, elles se résument en trois points :

- «La culture exige en premier lieu un certain équilibre entre les valeurs spirituelles et matérielles. Cet équilibre permet le développement d'une disposition sociale qu'on estime supérieure et plus élevée que ne l'est la simple obtention du nécessaire ou la satisfaction de l'ambition » (ibid. : 43). L'auteur refuse de « considérer [...] comme culture les civilisations primitives, ou inférieures ou plus grossières » (id.), mais il ne veut pas non plus « tomber dans une admiration exclusive des civilisations déjà très avancées ou dans la surestimation d'un facteur culture unique, que ce soit la religion, l'art, le droit, le pouvoir politique ou autre chose » (id.). Selon lui, il faut qu'il y ait une forme d'« harmonie des fonctions culturelles » (id.). Bien qu'il s'intéresse aux changements culturels et qu'il désigne certaines sociétés comme inférieures, son approche n'est pas celle d'un évolutionnisme strict et unilinéaire comme on a pu le trouver au XIX $X^{e}$ siècle. Cependant, il prône bien l'idée qu'un développement doit s'opérer pour conduire à une forme d'équilibre que constitue la culture et qui doit faire sortir les sociétés d'un état d'origine primitif ;

- « Le deuxième trait fondamental de toute culture, c'est qu'elle doit comporter une aspiration » (ibid. : 44). L'auteur entend par là une « direction vers un but, un idéal de toute collectivité ». II ajoute : «Que le but final se situe dans l'au-delà ou dans le proche avenir terrestre, dans la sagesse ou le bien-être, la condition pour 
le poursuivre ou l'atteindre sera toujours la sécurité et l'ordre. La tendance naturelle de toute culture comporte toujours impérieusement le maintien de cet ordre et de cette sécurité. [...] L'aspiration vers une culture quelconque se manifeste toujours dans de nombreux systèmes d'autorité et de droit » (ibid. : 45). Toute culture doit donc s'accompagner d'un certain nombre d'orientations qui doivent être garanties par ses institutions. L'aspect ordonné de la culture se retrouve dans le jeu qui est à son fondement. À ce propos, dans Homo Ludens (Huizinga, 1938 : | |4- |29), on retrouve un chapitre, intitulé « Le jeu et la juridiction », sur les liens entre les jeux et le droit déjà annoncés dans le premier chapitre ;

- enfin, la troisième condition : «Qui dit culture dit domination de la nature » (Huizinga, 1935 : 45). Par cela, l'auteur entend non seulement la nature comme environnement, mais aussi « la nature de l'homme » (ibid. : 47) afin de saisir « certaines obligations qui lui incombent » (id.). La culture est donc le dépassement d'une condition initiale. « L'obligation s'étend bientôt sous forme de tabous, de conventions, de règles de conduites, de cultes. L'emploi facile du mot tabou a conduit en de nombreux milieux à sous-estimer le caractère matérialiste du sens éthique des soi-disant civilisations primitives » (id.). Bien qu'utilisant ce terme en référence à l'école française de sociologie, il en condamne l'abus : « Encore laissons-nous de côté la tendance sociologique qui, pour juger tout ce qui s'appelle droit, morale, crainte de Dieu, verse le tout dans un récipient étiqueté "tabou" avec une légèreté toute moderne, même lorsqu'il s'agit d'une culture déjà développée » (id.). Johan Huizinga récuse l'amalgame entre certaines sociétés primitives et des sociétés plus avancées qui s'appuie sur l'usage de concepts génériques appliqués à toutes les formes de vies sociales. L'auteur met l'accent sur « la notion de service, indispensable à toute culture digne de ce nom » (ibid. : 48). Celle-ci commence « par le service de Dieu jusqu'à celui du prochain ». Dans cette citation, on découvre un auteur chrétien dont les interrogations sur les valeurs morales accompagnent la pensée scientifique. À ce titre, il convient de rappeler les dernières pages d'Homo Ludens, dans lesquelles Huizinga (1938: 290-292) discute les propos de Platon qui font de l'homme un jouet des dieux. Selon le Néerlandais, seule l'éthique qui fonde la morale et la justice permet de dépasser les limites que la logique ne peut franchir pour définir s'il faut se comporter de manière sérieuse ou comme dans un jeu.

La position de Johan Huizinga quant à ce que la culture doit être est avant tout morale. D'ailleurs, l'historien rappelle qu'il est important de retrouver des « valeurs éternelles » (Huizinga, 1935 : 243) servant de guide au-delà « de l'évolution et du changement ». La morale apparait avec la mise en place d'un ordre et d'obligations. Elle a une visée, un idéal et conduit à un équilibre matériel et spirituel, qui permet de se dégager d'un état initial chaotique. Rappelons que le chaos est aussi associé à la barbarie déjà évoquée à propos de la Première Guerre mondiale et qui s'oppose à l'idée de civilisation. Johan Huizinga craint une forme de régression qui renvoie à certaines conceptions évolutionnistes de la culture comme faisant partie de ce processus de civilisation. Celle-ci est liée à l'acquisition de bonnes mœurs, 
elle s'oppose à la barbarie et démontre le progrès d'un peuple vers un état jugé meilleur. Encore faut-il que ce progrès soit maitrisé. On retrouve cette idée dans À l'aube de la paix, dont le premier chapitre, intitulé «Terminologie du phénomène de civilisation 》 (Huizinga, 1945 : I I-24), est consacré au terme « civilisation » et où les termes « culture » et « civilisation » se rejoignent. Déjà évoquée, la vision anthropomorphique des sociétés se fonde sur l'idée que le processus de civilisation est une sortie d'un stade de jeunesse et dirige les peuples vers une forme de sagesse. Johan Huizinga (1938 : 37) fait ce même amalgame dans Homo Ludens à propos du jeu : « La communauté archaïque joue comme jouent l'enfant et l'animal. Cette opération, dès l'origine, est riche des éléments propres aux jeux : ordre, tension, mouvement, solennité, enthousiasme. Dans une phase plus évoluée seulement de la vie sociale s'associe à ce jeu la conception que quelque chose s'y trouve exprimé : une image de la vie ». L'idée d'« image de la vie » évoque la construction d'un sens particulier, à la fois signification et orientation, donné à des actions qui prennent place dans les formes évoluées de vie sociale. C'est par l'évolution de la vie sociale que permet le jeu que l'homme prendra conscience de la place qu'il occupe dans l'univers. Le jeu participe donc au fait de rendre possible une forme d'élévation spirituelle comme celle dont il est question dans la définition de la culture de l'auteur, qui aide à définir le sens que l'homme accorde à sa vie. Johan Huizinga poursuit alors : « $\mathrm{Ce}$ qui était un jeu dépourvu d'expression verbale prend une forme poétique. Dans la forme, et dans la fonction du jeu, qualité spécifique, la conscience qu'a l'homme d'être intégré dans le cosmos trouve sa première expression, la plus haute et la plus sainte. Dans le jeu pénètre peu à peu la signification d'un drame sacré. Le culte se greffe sur le jeu. Le jeu en soi fut toutefois le fait initial » (ibid.). II est donc une condition pour rendre possible l'émergence des formes du sacré, qu'il précède, et il permet à l'homme de se situer. Cela signifie que l'ordre est une des qualités principales du jeu. II permet de donner une place aux êtres et aux choses.

\section{Jeu, sacré et cercle magique}

On note avec intérêt que, dans Incertitudes, Johan Huizinga (1935) fait référence au terme « tabou » utilisé par les sociologues. Repris des travaux de Robertson Smith à la suite de James G. Frazer notamment (Borgeaud, I 994 : 397), l'idée de tabou a influencé les études de l'école française de sociologie. Elle est liée à celle d'interdits et, par conséquent, à celle de sacré (Hubert, Mauss, 1906: 16-17). D'ailleurs, Roger Caillois (1939b:77-125) consacre un chapitre entier, intitulé « Le sacré de respect :Théorie des interdits », de son ouvrage L'homme et le sacré à la question des interdits. Pour les sociologues français, considérée comme une différence « absolue » au-delà même de celle entre le bien et le mal (Durkheim, 1912 :53), l'opposition entre sacré et profane sert de fondement à l'institution religieuse qui est la première des institutions (Tarot, 2003 : 27I ; 2012 : 340-34I). Ces catégories servent à l'analyse de l'organisation de l'espace social et ces réflexions sont liées à la question des origines et de l'évolution qui conduit les peuples primitifs jusqu'aux 
civilisations plus avancées (Borgeaud, 1994: 389). Chez Johan Huizinga (voir supra), c'est le jeu qui, par son opposition à la vie courante, sert à poser des bases ordonnées de la culture et qui donne ses fondements au culte.

Un dernier point peut à présent être abordé, celui du lien entre le jeu et le sacré tel que proposé par Johan Huizinga. Cette idée se retrouve tout au long du premier chapitre d'Homo Ludens, intitulé « Nature et signification du jeu comme phénomène de culture » (Huizinga, 1938 : 15-50). En effet, chez Johan Huizinga (1938: 24), tout comme le sacré s'oppose au profane, le jeu s'oppose à la vie courante ; « il offre un prétexte à s'évader de celle-ci pour entrer dans une sphère provisoire d'activité à tendance propre ». L'esprit ludique devient organisateur d'espace physique et social : «De même qu'il n'existe point de différence formelle entre un jeu et une action sacrée, à savoir que l'action sacrée s'accomplit sous des formes identiques à celles du jeu, de même le lieu sacré ne se distingue pas formellement de l'emplacement du jeu. [...] Ce sont des mondes temporaires au cœur du monde habituel, conçus en vue de l'accomplissement d'une action déterminée » (ibid. : 26). C'est aussi le terme « mondes » séparés, sacré et profane, que l'on retrouve chez Henri Hubert et Marcel Mauss (I899: 30I) lorsqu'ils émettent l'hypothèse selon laquelle le sacrifice sert à établir une communication entre les mondes profane et sacré, dont François-André Isambert (1982 : 226) relève qu'il apparait chez les deux auteurs à la fois « comme champ sémantique, comme espace symbolique et comme système opératoire ». L'idée qui préside aux couples sacré/profane et jeu/vie courante est bien celle de deux cadres à la fois séparés et distincts, mais qui peuvent se rejoindre selon certaines modalités.

Pour Johan Huizinga (1938:26), le jeu précède le sacré et c'est en se développant en des formes plus évoluées qu'il pourra acquérir des significations sur lesquelles se grefferont des manifestations liées au sacré : «Quoi qu'il en soit, le jeu humain, dans toutes ses manifestations supérieures, où il signifie ou célèbre quelque chose, a sa place dans la sphère des fêtes et du culte, la sphère sacrée ». De cette façon, il acquiert un rôle et une utilité pour la communauté qui le pratique : « Comme action sacrée, le jeu peut servir la prospérité du groupe, mais alors d'une autre manière et avec d'autres moyens que l'acquisition immédiate d'éléments de subsistance » (ibid.). Ainsi, si le jeu est utile à la communauté, c'est qu'il n'est pas séparé de la vie courante au sens strictement littéral. Son rôle est plutôt d'ordre spirituel par opposition à l'idée d'éléments de subsistance comme la nourriture ou les biens matériels. Les rituels et les cultes adoptent la forme d'un jeu et en gardent par conséquent de nombreux traits. Ils permettent de donner formes à des choses normalement invisibles (ibid. : 32-33). Le jeu comme principe fondamental participe à faire de l'homme un être spirituel au-delà de sa nature terrestre. Cela renvoie à l'idée de culture développée dans Incertitudes selon laquelle les valeurs spirituelles y jouent un rôle au côté des valeurs matérielles et que, pour qu'il y ait culture, l'homme doit dominer la nature. Ainsi comprend-on mieux le rôle du jeu pour lutter contre la souffrance mentale et spirituelle (« geestelijk ») qu'évoque le titre original de l'ouvrage. 
Notons aussi que, selon Johan Huizinga, c'est par le jeu et son aspect de compétition que l'homme réalise son aspiration à s'élever au-delà des éléments terrestres, et ce, indépendamment des formes que prend la religion dans différentes sociétés (ibid. : I 13). Le jeu constitue une forme d'expérience subjective pour les participants, qui se construit dans le rapport à la communauté. Encore une fois, un rapprochement peut être effectué ${ }^{4}$ avec la notion du sacré comme force active découlant de ce qu'Émile Durkheim (cité in : Isambert, 1982:242-243) appelle la « communion des consciences » qui doit, selon lui, avoir « un certain degré d'unité, d'intimité, et que les forces qu'elle dégage soient assez intenses pour tirer l'individu hors de lui-même et l'élever à une vie supérieure ». Comme le sacré, le jeu sert à l'homme à dépasser le stade de son simple état d'être terrestre et naturel en en faisant un être spirituel. Encore une fois, cela sinscrit dans la continuité de la définition de la culture de son ouvrage précédent.

Ces nombreux rapports entre jeu et sacré permettent de mieux comprendre les sous-entendus de la définition du jeu telle que Johan Huizinga (1938:5 I) la propose : « Le jeu est une action ou une activité volontaire, accomplie dans certaines limites fixées de temps et de lieu, suivant une règle librement consentie mais complètement impérieuse, pourvue d'une fin en soi, accompagnée d'un sentiment de tension et de joie, et d'une conscience d"'être autrement" que dans la "vie courante" ». De cette définition, nous pouvons retenir quatre éléments importants : le jeu est une action volontaire, c'est-à-dire qu'on y participe par choix ; il est limité dans le temps et l'espace ; il est réglé ; il se situe hors de la « vie courante ». Pour ainsi dire, il organise les conventions sociales en définissant des espaces, des temporalités, les manières d'être et d'agir et leur donne du sens. Par son opposition à la vie courante, le jeu adopte donc chez Johan Huizinga les qualités que le sacré possédait chez d'autres chercheurs, notamment ceux de l'école française de sociologie. Tout comme chez Émile Durkheim (1912:65) pour qui l'opposition sacré/profane donnait naissance à la religion qui était la première de toutes les institutions, chez le Néerlandais, le jeu peut être à l'origine de l'ensemble des phénomènes qui seront explorés dans son ouvrage : compétition, droit, poésie, sagesse, mythes, philosophie, art, guerre. Comme les durkheimiens souhaitaient donner à la notion de sacré une valeur trans-historique et transculturelle (Isambert, 1982:215), Johan Huizinga (1938:52) rappelle que tous les peuples jouent « de manière notablement similaire ».

Mais c'est bien dans la forme que le jeu et le sacré se retrouvent, et Johan Huizinga le rappelle à plusieurs reprises : « Parmi les traits formels du jeu, la séparation locale de l'action par rapport à la vie courante en constituait le plus important. Un espace fermé est isolé, soit matériellement soit idéalement, séparé de l'entourage quotidien » (ibid. : 40). Ou encore, « formellement, la fonction de cette délimitation est exactement la même, qu'elle vise à des fins sacrées ou au jeu pur et simple. La piste, le court de tennis, le terrain de marelle, l'échiquier ne diffèrent pas formellement du temple ou du cercle magique » (ibid. : 40). L'historien se limite bien à une homologie de forme et non pas à une homologie de sens comme le lui reprocheront Roger Caillois (1946) et Émile Benveniste (1947), en lui faisant un faux procès.

\footnotetext{
${ }^{4}$ J. Huizinga ne cite pas lui-même É. Durkheim, c'est nous qui proposons ce rapprochement.
} 
On voit apparaître le terme « cercle magique » qui a fait couler beaucoup d'encre, notamment depuis sa reprise par Katie Salen et Eric Zimmermann (2003) dans leur ouvrage Rules of Play. La principale critique faite à l'encontre de cette notion est qu'un jeu n'est jamais totalement isolé du reste du monde. Cela peut paraître évident, mais Eric Zimmermann (2012) est revenu sur ce problème. Comme il l'écrit, personne n'a jamais cru cela, et surtout pas Johan Huizinga lui-même, puisque - comme nous l'avons vu - celui-ci disait qu'il pouvait servir à la prospérité de la communauté. Mais cette notion semble en quelque sorte servir d'« épouvantail » («Straw man » - ibid.) qu'agitent les chercheurs du domaine. En outre, Eric Zimmerman insiste sur le fait que personne ne pense sérieusement qu'un jeu puisse exister en dehors de tout environnement. Simplement, en tant que game designer, penser un jeu comme un système clos s'avère parfois nécessaire, mais uniquement dans un horizon de pertinence particulier. Dans ce cas, il s'agit donc d'une simplification conceptuelle qui permet de penser les limites ou les marges d'une production.

On voit mieux comment ces lectures complémentaires permettent d'envisager les implications qui sous-tendent l'étude du jeu de l'historien. Grâce à elles, on comprend qu'une telle conception de la notion « culture » n'est pas compatible avec des conceptions plus neutres sur le plan moral, telles des positions de relativisme culturel ou encore des conceptions pragmatiques et interactionnistes comme celle d'Howard S. Becker (1999:21) pour qui la culture est un ensemble d'attentes et de ressources constamment actualisées, servant à coordonner les activités des individus, et qui varie sans cesse en fonction des situations. Chez le sociologue américain, elle n'a pas vocation à conduire les sociétés vers quelque chose de « meilleur » ou à fixer un idéal. Cette position situationniste et constructiviste serait plus proche des travaux sur le jeu de Jacques Henriot (Genvo, 2013 : 2). Pour qui veut construire un cadre heuristique cohérent, il est donc important de s'arrêter sur ces définitions de concepts centraux tel celui de culture. La position de Johan Huizinga traduit d'abord des idéaux. Bien sûr, il n'y a rien de mal à vouloir faire évoluer la société dans un sens positif, seulement, il faut garder à l'esprit et exposer clairement qu'il s'agit d'une position morale, donc loin d'être neutre, méritant d'être débattue sur le plan des valeurs.

\section{Roger Caillois, le jeu et le sacré dans la sociologie française}

Sociologue, essayiste, critique littéraire et écrivain français, Roger Caillois est né en $1913^{5}$. II est agrégé de grammaire et fait office de personnage multi-casquettes dans le champ intellectuel. Jeune, il adhère au mouvement surréaliste d'André Breton avant de s'en retirer publiquement à la suite de l'affaire des haricots

\footnotetext{
5 Le lecteur pourra se référer aux archives vidéo sur la vie de R. Caillois: Archives du xx siècle. Roger Caillois. Partie I, 1977 (accès : http://www.ina.fr/video/CPA77058863; consulté le 05/05//4) et Archives du xx siècle. Roger Caillois. Partie 2, 1977 (accès : http://boutique.ina.fr/video/histoireet-conflits/autres-conflits/CPA77058864/roger-caillois-2eme-partie.fr.html.; consulté le 05/05/I4).
} 
sauteurs $^{6}$ (Caillois, 1974a : I I). Par ailleurs, il suivra les enseignements de sociologie religieuse de Marcel Mauss, ainsi que les cours de Georges Dumézil (Felgine, 1994 : 86-89). C'est de là que lui vient son intérêt pour le sacré qui le rattache à Émile Durkheim, Henri Hubert et Robert Hertz, comme il le mentionne dans la préface de L'homme et le sacré (Caillois, 1939b : 19) et dans Approches de l'imaginaire (1974a : 58). Chez Roger Caillois aussi, les questions relatives au sacré sont liées à celle des origines et à ce qui conduit ceux qu'on appelle parfois encore les peuples primitifs à la civilisation. Avec notamment Georges Bataille et Michel Leiris, il fonde en 1937 le Collège de sociologie dont il écrit le manifeste (Caillois, 1974a : 70-72) dans lequel il affirme vouloir proposer une sociologie « activiste » du sacré que les membres nomment d'ailleurs « sociologie sacrée », dont le but est de redonner de la vigueur à leur société. L'idée de communauté tient à ce titre une place centrale dans les recherches des membres de ce collectif. Plus tard, Roger Caillois (1974a: 58) expliquera leurs influences : « Nous étions certes d'accord sur l'importance éminente, sinon décisive, du sacré dans les émotions des individus comme dans la structure des sociétés ». On discerne alors ce croisement entre les approches de l'école française de sociologie et celle, phénoménologique, de Rudolf Otto'. Enfin, notons que Roger Caillois regroupera ses ouvrages L'homme et le mythe (1938), L'homme et le sacré (1939b) Les jeux et les hommes (1958b) et quelques autres - de moindres importances pour la présente contribution - sous une même étiquette qu'il appellera sa « parenthèse sociologique » (Caillois, 1974a : 60). Dans la préface à la troisième édition de L'homme et le sacré, écrite en 1963 (Caillois, 1939b : I4), il indique que l'annexe intitulée « Le jeu et le sacré » aboutit à son livre Les jeux et les hommes. Cela influe sur les objectifs de ses théories du jeu et la portée qu'il souhaite leur donner. II ne faut donc surtout pas négliger cet aspect afin de comprendre les liens que l'auteur établissait lui-même entre ses différents travaux.

\section{Le ludique et le sacré}

Au vu des éléments évoqués, il semble évident que Roger Caillois ne pouvait pas rester insensible au livre de Johan Huizinga $(1938)^{8}$. En proposant une théorie du jeu en rapport avec le sacré et comme étant au fondement de toute organisation sociale, ce dernier provoque l'intérêt du sociologue français. Rappelons que pour ce dernier, le sacré se définit avant tout par son opposition au profane

\footnotetext{
${ }^{6}$ Les « haricots sauteurs » ou « pois sauteurs » du Mexique sont des graines dans lesquelles une espèce de papillon pond ses œufs. Après éclosion, l'activité des larves à l'intérieur fait sautiller les graines. En I934, à Paris, A. Breton et R. Caillois sont tous deux face à ce type de graines. Tandis que R. Caillois souhaite en ouvrir une pour découvrir la chenille et percer l'énigme, A. Breton s'y oppose car il préfère continuer à jouir du mystère. Cette controverse nommée l'affaire (ou querelle) des haricots sauteurs fut révélatrice des divergences existant entre les deux hommes quant à la conduite à adopter face au merveilleux.

7 Pour une explication des différences entre les deux approches, voir notamment F.-A. Isambert (1982), P. Borgeaud (1994) et C. Tarot (2003, 2012).

8 T.Wendling (à paraître : 213 ) note également que, en plus du lien avec le sacré, l'ancrage politique des théories de J. Huizinga face au nazisme avait pu faire écho aux motivations du Collège de sociologie.
} 
dans une conception religieuse du monde (Caillois, 1939b : 23). Deux « milieux complémentaires » ou deux « mondes » qui « ne se définissent rigoureusement que l'un par l'autre » (ibid. : 23-24) se constituent en se fondant sur cette distinction. On retrouve les termes d'Henri Hubert et de Marcel Mauss ( 1899 ). Roger Caillois désigne le sacré comme une propriété ou une qualité, stable ou éphémère, accordée à des êtres, des choses, des espaces, des temps, qui contribue à définir l'attitude qu'il convient d'adopter dans le rapport que les individus entretiennent avec leur environnement (ibid.). La distinction sacré/profane sert donc à comprendre les constructions de sens qui définissent des normes et guident l'action des individus. Cette conception particulière de l'étude des sociétés oriente la conception du jeu de Roger Caillois vers une approche qui intègre le sens accordé au jeu au-delà d'une simple étude de forme.

Selon Thierry Wendling (à paraitre : 209-210), les premières évocations du thème du jeu apparaissent chez Roger Caillois (1939a : 645-693) dans un texte de 1939 consacré à la fête 9 . Le sociologue y évoque les jeux de hasard qui, durant le temps de fête, sont des activités de risque et de dilapidation qui s'opposent directement au temps de travail où l'on accumule des richesses de manière lente et sûre. II est possible d'établir un rapprochement entre cette proposition et le caractère improductif du jeu dont Roger Caillois ( 1958b : 36) dit qu'il « est l'occasion d'une dépense pure ». Faisant partie du temps sacré, le jeu s'oppose à la vie courante. Pour lui, la fête est aussi liée au sacrifice (Caillois, 1939a :646) et il essaie de mettre en lumière « l'atmosphère sacrificielle 》 de la fête. II fait une nouvelle fois référence aux théories du sacré d'Henri Hubert et de Marcel Mauss (1899). De plus, il puisera dans les enseignements de Marcel Granet, ainsi que dans d'autres travaux de Marcel Mauss sur le rapport entre jeux et mythes cosmologiques, effectués à la fin des années 30, où il cherchera des exemples pour nourrir sa critique du livre de Johan Huizinga (Wendling, à paraître : 215). Son intérêt pour l'auteur néerlandais pourrait, entre autres raisons, lui être venu d'une présentation de Denis de Rougemont au Collège de sociologie (ibid. : 2II-2I2). Celui-ci y présentait le tournoi chevaleresque comme un jeu du mythe et y évoquait les travaux du Néerlandais sur le Moyen Âge. Des parcours individuels s'entrecroisent avec des intérêts pour des thématiques particulières qui circulent ainsi entre chercheurs. Cependant, chez Roger Caillois, la thématique du jeu restait encore marginale et s'intégrait à d'autres réflexions sur le sacré et son expression dans la fête. II faut attendre l'après-guerre pour que les choses changent.

\footnotetext{
9 Ce texte deviendra peu après la partie consacrée à la fête dans L'homme et le sacré (Caillois, 1939b) et subira des modifications lors de rééditions ultérieures de l'ouvrage après-guerre (Hollier, 1979:642). II est aussi possible de noter que R. Caillois (1958b : 62-63) reprend des exemples tirés de son livre L'homme et le mythe sur le mimétisme animal pour nourrir sa réflexion sur la mimicry. Stéphane Massonet (1998: 192) note une évolution dans l'orientation générale de ses recherches car « en lui permettant de considérer la différence de nature entre jeu et sacré, le jeu réactualise l'ensemble de ses recherches sur le mimétisme des insectes, non plus dans l'horizon du mythe et du sacré, mais dans la perspective d'un ludisme qui va bientôt déborder la sphère sociologique ou anthropologique vers celle d'un jeu cosmique ».
} 
Intitulé « Le ludique et le sacré », le premier article que Roger Caillois consacre entièrement à la question du jeu, est publié en 1946 dans la revue Confluences. II sera republié sous un titre légèrement différent dans la seconde édition de L'homme et le sacré, parue en 1950. L'auteur y reprend et critique la thèse principale de Johan Huizinga sur le lien entre jeu et sacré. En effet, pour le Français, les deux phénomènes ont en commun le fait d'être « un espace clos délimité, séparé du monde et de la vie » (Caillois, 1946 : 69). Les deux concepts se rejoignent donc sur le plan de la forme. Cependant, contrairement au sacré, « le ludique, activité libre par excellence, est le profane pur » (ibid. : 75). Sacré et jeu s'opposent alors de façon symétrique par rapport à la vie courante dont ils se distinguent (ibid.). Une théorie similaire, dont Roger Caillois prendra connaissance plus tard, sera développée quasi simultanément par Émile Benveniste (1947 : 164) pour qui le jeu et le sacré « ont en fait une structure symétrique, mais opposée » et dont la conséquence est que « le sacré est sur-réel, le jeu, de l'extra-réel » (ibid.). Le jeu ne serait « donc au fond qu'une opération désacralisante » (ibid. : I65) qui en ferait du sacré inversé. C'est ici sur le plan du sens que le sociologue et le linguiste opèrent une distinction. Roger Caillois (1946:68) voit là « le défaut de cet ouvrage admirable » en rappelant qu'« il étudie des structures externes bien plus que les attitudes intimes qui donnent à chaque comportement sa signification la plus précise ». II faut rappeler que, pour le Français, qui s'inspire également des travaux de Rudolf Otto (1917), le sacré attire grâce à une sorte de « don de fascination » (Caillois, 1939b : 27) et que son « monde [...], entre autres caractères, s'oppose au monde du profane comme un monde d'énergies à un monde de substances. D'un côté, des forces; de l'autre, des choses » (ibid. : 44). Cette définition renvoie à la théorie du mana, élaborée par Robert $\mathrm{H}$. Codrington et reprise par Henri Hubert et Marcel Mauss (1902-1903: 101-102) dans leur théorie de la magie, selon laquelle il s'agit d'une force active et efficace qui imprègne toute chose et leur donne une certaine valeur. Roger Callois (1946: 72) rappellera dans son article sur le jeu que le sacré est « contenu pur : force indivisible, équivoque, fugitive et efficace ». C'est pour cette raison qu'elle nécessite d'adopter face à elle une attitude empreinte de respect, tandis que dans le jeu, au contraire, l'homme serait créateur et enjoint à la détente, au repos ou à la distraction.

Dans Les jeux et les hommes, Roger Caillois (1958b : 3 I) revient aux thèses de Johan Huizinga qu'il considère comme « fécondes à la recherche et à la réflexion » pour avoir notamment « démontré l'importance [du rôle du jeu] dans le développement même de la civilisation » (ibid.). II s'accorde alors avec l'historien néerlandais sur l'idée d'établir une théorie générale de l'origine et de l'évolution des sociétés humaines. Cependant, il précise que, pour qu'il y ait jeu dans le cas de jeux fondés sur le mystère, le secret ou le travestissement, il faut que « la part de la fiction et du divertissement l'emporte » (ibid. : 34). Roger Caillois confirme ainsi un rapport entre des formes analogues que peuvent prendre le jeu et le sacré, mais, par la même occasion, il renouvelle sa critique selon laquelle l'attitude face à l'activité doit être celle de la détente plutôt que du respect révérencieux. D'ailleurs, le chapitre sur « La corruption des jeux » (ibid. : I0I-122) rappelle le 
risque de mélange et de contagion par le profane qui menace parfois le sacré, et inversement, et que Roger Caillois (1939b : 32-33) avait déjà développé dans un autre ouvrage. Selon le sociologue, il peut aussi y avoir contamination entre le jeu et le « monde réel ». On retrouve ici la critique faite dans son premier article.

Cette réflexion suivra Roger Caillois ( 1967 : VII-VIII) jusque dans l'encyclopédie qu'il dirige dans la collection de la Pléiade. Dans cet ouvrage, l'auteur (ibid. : 9) évoque l'hypothèse selon laquelle certains jeux sont des survivances d'éléments culturels, faisant partie d'institutions laïques ou sacrées qui, privées de leur sens car éloignées de leur culture d'origine, ont dégénéré en jeu. On pourrait penser que cette dégénérescence, notamment du sacré dans le jeu, serait un signe de l'évolution des sociétés. Cependant, l'homme nuance son propos en prenant des exemples dans lesquels les enfants imitent des éléments de culture contemporaine sur le mode ludique. À ce sujet, il cite les pistolets à eau qui imitent les armes à feu, ou le fait que des enfants catholiques peuvent jouer à la messe. II en conclut « que le jeu n'est nullement le résidu anodin d'une occupation d'adulte désaffectée, encore qu'il en perpétue éventuellement le simulacre, quand elle-même est périmée. II se présente avant tout comme une activité parallèle, indépendante, qui s'oppose aux gestes et aux décisions de la vie ordinaire par des caractères spécifiques qui lui sont propres et qui font qu'il est un jeu » (ibid. : I I). Ainsi confirme-t-il son idée selon laquelle sacré, vie courante et jeu constituent des cadres distincts qui, bien qu'adoptant parfois des formes similaires, se distinguent sur le plan du sens qu'on leur accorde. Or, Johan Huizinga évoquait uniquement la forme des rites et du culte qui dérivait du jeu lorsque celui-ci évoluait, mais ne traitait pas d'une similitude de sens. D'ailleurs, il avait conscience des différences de signification. La critique de Roger Caillois et d'Émile Benveniste semble donc mal placée après une relecture attentive. Néanmoins, elle permet de relever que, bien avant de proposer sa typologie des jeux, Roger Caillois offre une réflexion sur la place du jeu dans les processus de civilisation et sur son rôle d'élément organisateur de la vie sociale. Mais, contrairement à Johan Huizinga, chez le Français, le jeu n'a pas la primauté sur le sacré : il s'agit de deux sphères d'activité à la fois « parallèles », distinctes et opposées sur le plan du sens.

\section{La querelle avec Claude Lévi-Strauss}

Entre son premier article et son ouvrage Les jeux et les hommes, certaines choses ont évolué dans la pensée de Roger Caillois. Au milieu des années 50, le sociologue (Caillois, 1954, 1955a, 1955b) s'oppose à Claude Lévi-Strauss (1955a, 1955b) dans une critique de l'ouvrage Race et histoire (Lévi-Strauss, 1952) : « Sur le plan des idées, il s'agit pour Caillois de rappeler la supériorité de l'Occident et pour Lévi-Strauss de défendre une approche des civilisations dégagée de tout ethnocentrisme » (Wendling, 2010:31). Cette polémique et ses conséquences ont été brillamment analysées par Michel Panoff (1993) et Thierry Wendling (20l0) sur le fond comme sur la forme. Nous ne reviendrons donc pas sur les 
détails de l'affaire. Cependant, on peut noter que les deux auteurs affichent une préférence nette pour Claude Lévi-Strauss ${ }^{10}$. Ce que nous suggérons est qu'un autre élément, qu'il ne faut pas négliger, peut intervenir dans cette discussion, car elle se déroule précisément durant les années où Roger Caillois (1955c) commence à élaborer de manière plus concrète ses théories des jeux et sa typologie. Si, pourThierry Wendling (20 I $0: 29$-30), cette opposition a notamment eu pour conséquence un désintérêt de l'ethnologie pour le jeu durant la période structuraliste, il faut aussi mettre cette querelle en lien avec les orientations prises par Roger Caillois pour élaborer sa théorie des jeux qui s'ancrent dans la continuité de ses réflexions sociologiques sur le sacré. En effet, cette polémique se produit dans un « contexte de filiations intellectuelles complexes » (Wendling, 2010 : 30) où la question du sacré et les conceptions du monde qu'elle soustend, comme celle d'une forme d'évolutionnisme, ont pu influencer le débat. D'un point de vue de sociologue des religions, Camille Tarot (2012:348) suggère que le succès du structuralisme a provoqué un désintérêt pour le sacré dans la deuxième moitié du $x x^{e}$ siècle. En croisant ainsi les recherches de Camille Tarot avec celles de Thierry Wendling, on trouve un argument de plus, qui semble confirmer le sens de la lecture à donner aux travaux de Roger Caillois et ses effets dans le champ de la recherche française. Une séparation s'opère : d'une part, les études sociologiques sur le jeu poursuivent l'étude du sacré ; d'autre part, l'ethnologie se concentre sur le symbolique et des objets d'étude tels les mythes, la parenté et l'organisation sociale (Wendling, $2010: 47$ ).

\section{Une sociologie à partir des jeux}

C'est dans ce contexte de polémique avec les ethnologues que Roger Caillois (1958b : | 42) constitue sa théorie des jeux qui aboutit à l'ouvrage Les jeux et les hommes dont il présente ainsi le programme : « Je n'entreprends pas seulement une sociologie des jeux. J'ai l'idée de jeter les fondements d'une sociologie à partir des jeux ».

Dans son article, « Le ludique et le sacré », Roger Caillois (1946:67) reprochait déjà à Johan Huizinga de ne pas avoir abordé « les diverses attitudes mentales que supposent les différentes variétés de jeux : d'adresse, de force, de combinaison, de hasard, etc. »). C'est ce qui le conduit à proposer presque dix ans plus tard (Caillois, 1955c) une typologie des jeux où l'on retrouve ses catégories fondamentales: l'agon, l'alea, la mimicry et l'ilinx. Dans ce texte, l'ilinx tient une place un peu à part. Arrivant à la fin du texte, dans les mots de l'auteur, il est d'abord symptomatique de la modernité : « II reste une dernière espèce de jeux qui ne semble pas pouvoir

${ }^{10}$ C'est dans ses remarques sur Les jeux et les hommes (Caillois, 1958b) que M. Panoff (1993: 77) critique le plus R. Caillois, se demandant si c'est par sa « paresse », son « outrecuidance », ou son « aversion pour les ethnologues professionnels » que l'auteur pèche. M. Panoff mettra plusieurs fois les erreurs de R. Caillois sur le compte du manque de travail rigoureux qui, selon lui, le caractérise. 
rentrer dans celles-ci et qui peut passer pour la seule innovation proprement moderne en ce domaine : ceux qui reposent sur la poursuite du vertige » (Caillois, 1955c : 85). Bien qu'il reconnaisse que les sensations de vertige sont sans doute recherchées depuis longtemps, il affirme : « II ne faut donc pas s'étonner qu'on ait dû attendre l'âge industriel pour voir le vertige devenir véritablement une catégorie du jeu » (ibid.). C'est deux années plus tard, dans un article publié dans sa revue Diogène (Caillois, 1957 : | 36), qu'il parlera de sociétés « gouvernées par les forces conjuguées du masque et de la possession, ou, si l'on préfère, de la pantomime et de l'extase (mimicry et ilinx) et qui n'ont pas encore accédé à une vie collective fondée sur des institutions où la concurrence réglée et la compétition organisée jouent un rôle essentiel ». L'auteur poursuivra cette théorie dans un article publié l'année suivante (Caillois, 1958a), qu'il reprendra d'ailleurs presque mot à mot" dans Les jeux et les hommes (Caillois, 1958b : 45-92), où l'ilinx devient, avec la mimicry, la catégorie renvoyant aux « sociétés à tohu-bohu » (ibid. : |7|). II observe alors que « chaque fois qu'une haute culture parvient à émerger du chaos originel, on constate une régression des puissances de vertige et de simulacres » (ibid. : 193). Roger Caillois semble encore peu au clair sur l'idée qu'il se fait du vertige, qui apparaît, d'abord, comme un effet de la modernisation des techniques, avant de devenir une catégorie de jeu des sociétés primitives tendant à disparaitre avec le progrès. De plus, il établit un parallèle avec sa théorie du sacré selon laquelle l'ordre du cosmos émerge du chaos originel grâce aux forces sacrées et alors seulement « l'ère du tohu-bohu est close, l'histoire naturelle commence, le régime de la causalité normale s'installe » (Caillois, 1939b : 139). On peut donc déduire que, à ses yeux, les sociétés qu'il appelle « à tohu-bohu » seront plus proches de l'état originel chaotique.

Comme on le voit, en proposant sa sociologie « à partir des jeux », Roger Caillois souhaite faire valoir un modèle d'évolution des sociétés, ou de civilisation, qui viennent appuyer les arguments qu'il opposait précédemment au relativisme culturel développé par Claude Lévi-Strauss, contre lequel il s'était insurgé. Stéphane Massonet (1998: 187) estime que « cette seconde partie [de l'ouvrage Les jeux et les hommes] constitue une réponse implicite au débat sur le relativisme culturel qui l'opposa quelques années auparavant à Claude Lévi-Strauss ». Michel Panoff (1993 : 75), qui avait bien relevé ce problème, allait plus loin dans sa critique, dénonçant le « manque d'originalité intellectuelle », le fait qu'« il est difficile d'y trouver des idées personnelles » (ibid.) et que l'« appareil érudit est ici d'une légèreté déconcertante » (ibid.). Michel Panoff lui reproche de ne s'appuyer que sur des théories datées, faisant fi de tous les progrès, aussi bien en anthropologie qu'en zoologie, depuis le XIX $x^{e}$ siècle ${ }^{12}$. D'ailleurs, il signale que, en présentant le jeu

\footnotetext{
"Le lecteur peut remarquer, non sans une pointe d'humour, que R. Caillois reprend une bonne partie de son texte précédent. La phrase tirée de l'article de 1955 se voit ajouter un unique mot et devient alors : « II ne faut donc pas s'étonner qu'on ait dû souvent attendre l'âge industriel pour voir le vertige devenir véritablement une catégorie du jeu » (Caillois, 1958a : 95 ; nous soulignons).

12 On peut noter que R. Caillois (1938:82-85) établissait déjà un lien entre la mante religieuse et les mythes des femmes dévoreuses d'hommes, ou aux organes sexuels dentés, sous prétexte d'une
} 
comme un «phénomène total », Roger Caillois se situe plus dans la lignée de Marcel Mauss que Claude Lévi-Strauss qui, pourtant, signe la préface de Sociologie et anthropologie (Panoff, 1993:75-76). Or, c'est par la médiation et dans la continuité de Johan Huizinga (1938: 90), qui s'appuyait lui-même sur les travaux de Marcel Mauss (1923-1924) sur le Potlatch, que Roger Caillois présente le jeu. Alors, bien que « l'idée [soit] originale et d'une grande portée » (Panoff, I993:80-8I), elle n'est pas de lui. On la retrouve déjà tout entière chez l'auteur néerlandais.

Finalement, on peut avancer que l'ouvrage de Roger Caillois développe et élabore certains aspects déjà présentés par Johan Huizinga. De sa définition en six points du jeu (libre, séparé, réglé, incertain, improductif, fictif) quatre étaient déjà présents dans les travaux de l'auteur néerlandais. Concernant l'improductivité, nous avons vu que Johan Huizinga situait les apports du jeu sur le plan spirituel et non matériel. De même, il avait déjà présenté les bases de ce qui allait constituer les catégories de l'agon et de la mimicry chez l'auteur français, l'alea ne pouvant apparaître comme une catégorie fondamentale ou un type de jeu puisque, pour l'historien, le jeu est un facteur organisateur, voire ordonnateur, de vie sociale. Cela renvoie directement à la deuxième condition nécessaire de la culture selon sa définition. D'ailleurs, dans les exemples qu'il utilise, les jeux de dés peuvent servir à régler une compétition et une lutte (Huizinga, 1938 : 82). Le hasard est donc une forme d'incertitude fondamentale, et le jeu, sous ses diverses formes, une manière de faire face à celle-ci ou de l'utiliser, donc d'avoir une prise sur elle. Ici, Roger Caillois montre une mauvaise compréhension de la pensée de Johan Huizinga en mélangeant les niveaux d'interprétation, mais, plus grave encore, ce biais rend incohérent sa propre pensée et permet d'émettre une nouvelle critique à l'encontre de sa typologie. En effet, le hasard pur ne peut pas être considéré comme principe ordonnateur puisque, par définition, il est son contraire et se fonde sur l'indétermination et l'incertitude. II renvoie alors à la question des limites de la perception humaine ${ }^{13}$.

Enfin, l'ilinx passe du statut de type de jeu foncièrement moderne à celui de type primordial, comme s'il s'agissait de justifier l'évolution des sociétés par un équilibre d'oppositions binaires, mimicry et ilinx du côté des « sociétés à tohubohu », alea et agon du côté des « sociétés à comptabilité » (Caillois, 1958b : 172). C'est sur ce point qu'il se démarque de l'auteur néerlandais, en proposant une classification des sociétés selon leurs jeux. Malheureusement, le résultat semble précéder la démonstration et l'opposition proposée peut paraitre artificielle. D'ailleurs, c'est le reproche le plus important à faire à sa classification des jeux, puisqu'elle constitue une typologie généralisée posée a priori et ne correspond à aucune véritable démonstration, mais à une synthèse empreinte de présupposés (Wendling, 2002 : 43). On retrouve exactement le problème qu'il soulève luimême à propos de sa théorie du sacré, à savoir, le « côté fallacieux et grossier d'une telle entreprise » (Caillois, 1939b : 17). Cette dernière présente des règles

continuité dans le vivant, le mythe se situant dans le prolongement des instincts primordiaux.

13 À ce sujet, voir les travaux d'lvar Ekeland (1991). 
qui ne s'appliqueraient jamais intégralement, ses conclusions ne sont valables que pour la moyenne des faits, ses descriptions sont sorties de leurs contextes et ne sont pas beaucoup plus que des abstractions (ibid. : I 8). Ces critiques pourraient s'appliquer de la même façon à sa typologie des jeux. Bien que dans le cadre d'un essai, proposer des hypothèses soit une méthode de travail féconde, à aucun moment, lui-même ne la présente ainsi. Ceci conduit à des reprises de ses théories sans remise en question des fondements mêmes de sa classification tels que nous les avons présentés. Tout au plus, on objectera une critique des six points de sa définition du jeu et les limites des alliances possibles qu'il propose entre les différents types de jeu, ces critiques se faisant d'ailleurs souvent sans une remise en contexte historique de ses travaux (Triclot, 201 I :46). Ainsi a-t-on parfois l'impression que l'on reproche à Roger Caillois de ne pas tenir compte de jeux qui n'existaient pas à son époque, tels les jeux vidéo.

Comme on le voit, Les jeux et les hommes participe en grande partie à cette guerre que Roger Caillois (1958b : 183) fait aux ethnologues, « savants dont la crédulité est, hélas! infinie, et, en outre, intéressée, envoûtée ». Comme le relève Michel Panoff (1993, 80-81), « ce qui restait encore implicite dans la querelle qu'il avait cherchée à Lévi-Strauss quatre ans plus tôt s'exprime désormais sans détour ni nuances ». D'ailleurs, les traces de cette querelle resurgiront bien des années plus tard lorsque Roger Caillois (1974b) accueillera Claude Lévi-Strauss à l'Académie française. II ne pourra s'empêcher de rappeler ce qu'il pense des ethnologues, reprenant de nombreux arguments déjà présents dans sa critique de Race et histoire. La remise en question de ses théories du jeu et de sa classification doit alors conduire à une discussion de son modèle sociologique général d'évolution des sociétés et, à l'inverse, des conceptions différentes de modèles sociaux généraux devront nourrir la critique des catégories qu'il propose. Son opposition duelle renvoie à la problématique déjà ancienne de l'altérité et du regard porté sur les autres peuples que Tzvetan Todorov (1989) a résumée sous la formule «Nous et les autres ». Qu'on les considère barbares dans l'antiquité, païens au Moyen Âge, sauvages à la renaissance, primitifs au XIX siècle ou « sociétés à tohu-bohu 》 au milieu du $x x^{e}$ siècle, l'idée principale qui se dégage est celle d'une différence constitutive ou d'une forme de distance dans le regard que l'on porte sur eux, c'est-à-dire de la construction d'une forme d'altérité. Dans son discours de réception à l'attention de Claude Lévi-Strauss, Roger Caillois ( 1974b) parle encore d'« hommes de nature » et de « population sauvage » lorsqu'il évoque l'idée selon laquelle l'ethnographie « se présente comme la seule science qui contribue à détruire son objet [...]. Car les sujets de l'étude ne peuvent pas ne pas rejoindre les savants qui les étudient ». Selon lui, toute technologie plus efficace qu'une autre finit toujours par supplanter la précédente, qu'il s'agisse de la hache d'acier qui remplace celle de pierre ou de l'arrivée du béton et de l'électricité dans la construction d'habitation. Roger Caillois défend l'idée d'une marche de l'histoire vers le progrès et l'échelle de valeurs sur laquelle il se situe est celle du progrès technique occidental. Dans Les jeux et les hommes, il traitait déjà des « transitions 》 (Caillois, 1958b : 199-216) d'un type de société vers l'autre qui permettait la sortie du piège que constituent 
la pantomime et l'extase et qui « n'est rien d'autre que la naissance même de la civilisation » (ibid. : 195). À propos de cette bipartition, Stéphane Massonet (1998: 202) rappelle qu'elle a valu à Roger Caillois les critiques de plusieurs ethnologues puisqu'il insiste « sur le passage d'une forme sociale à une autre, comme accès à la civilisation, comme si les sociétés primitives à masques, tout en formant un "type original de culture", n'étaient pas des formes de civilisations »».

On pourra opposer la vision relativiste de Lévi-Strauss (1952 : 32) considérant « qu'il n'existe pas de peuple enfant » et que, dans l'histoire, si l'échelle de mesure est le temps, des peuples aux coutumes variées sont contemporains les uns des autres sans pour autant que l'on doive considérer que certains vivent jusque-là au ralenti. II n'y a pas qu'une façon de comparer les sociétés entre elles et, comme l'écrit Franz Boas (1928: 207), « les valeurs de nos idéaux sociaux vont ainsi gagner en précision par une étude rigoureuse et objective des cultures étrangères $\rangle^{14}$. II faut aussi souligner que de nombreux peuples n'ont pas simplement adopté les techniques occidentales, mais ont souvent été contraints de se conformer à de nouveaux modèles culturels. Dans une approche qui se voudrait relativiste, il n'est donc pas possible de simplement diviser les sociétés en deux types en fonction des jeux qui y sont joués; chacun a ses spécificités et peut proposer des catégories de jeu qui lui sont propres. Chaque activité ludique doit ainsi être recontextualisée dans un temps et un espace particuliers. Nous rejoignons ici les propositions faites par Patrick Schmoll (20 I I) et Jacques Henriot ( 1989) citées plus haut. Ainsi le port du masque lors de carnavals ou les fêtes foraines dans les sociétés contemporaines n'est-il pas une simple « résurgence », ni le signe d'un retour en arrière à des sensations primordiales, mais pose plutôt la question de leur transformation, de leur fonction et de leur place par rapport à d'autres activités. Par exemple, on peut chercher à comprendre, comme le fait Paul Yonnet (1999), comment s'organise l'équilibre entre temps de travail contraint et temps de loisir plus libre. On peut également envisager les processus d'emprunts ludiques entre différentes cultures. II ne s'agit plus alors d'une étude d'états, mais de celle de processus et d'activités toujours en mouvement. Ainsi évite-t-on d'essentialiser certains concepts ou certaines catégories, comme le fait Roger Caillois. À ce propos, notons que les catégories sacré et profane ne s'appliquent pas rigoureusement à toutes les sociétés. François-André Isambert (1982 : 265-266) note que « non seulement cette fameuse notion commune n'a pas l'invariabilité qu'on lui a prêtée [...] mais encore que le sacré, comme concept de sociologue, ne correspond pas au mode de structuration de toutes les religions ». II serait alors possible d'appliquer son conseil au concept du jeu : «Dès lors, loin de vouloir se donner des concepts génériques applicables en tous temps et en tous lieux, quitte à y faire entrer tant bien que mal les faits les plus proches de nous, mieux vaut se saisir des relations caractéristiques qui se dégagent de nos contacts avec la réalité, en reconnaissant leurs racines dans notre expérience proche et en posant seulement ensuite la question de leur application possible à des domaines plus éloignés » (ibid. : 266).

14 « The values of our social ideals will thus gain in clarity by a rigid, objective study of foreign cultures ». 
Une autre position relativiste, que l'on retrouve dans certaines approches pragmatiques, consiste à voir chaque individu comme étant construit par ses expériences spécifiques. Ainsi chacun est-il différent et chaque situation particulière. La question du sens ou de la fonction des activités ludiques se pose au niveau de l'interaction et le sens donné aux situations y est construit de manière subjective et locale. Chaque activité devient alors une situation particulière dont le sens est sans cesse retravaillé. L'activité ludique prend son sens dans son rapport à la biographie des acteurs et dans un contexte particulier et non dans un modèle général de société.

\section{La question du modèle général}

La portée universelle que Johan Huizinga et Roger Caillois cherchent à donner à leurs études respectives risque de conduire à la dérive consistant à placer sous une même notion des phénomènes variant dans le temps et l'espace. Cela est principalement dû au fait d'utiliser un ou des termes polysémiques avec une portée générale et à celui de donner un caractère universel à une vision ethnocentrée. II faut donc remettre en question leurs définitions a priori du jeu, ainsi que la volonté des deux chercheurs de réunir sous un même vocable des phénomènes somme toute variés. Les deux auteurs ne distinguent pas de façon nette les deux sens du mot « jeu » : objet ou activité. Au contraire, ils jouent sur l'ambiguïté sémantique du terme ${ }^{15}$. Jacques Henriot $(1969,1989)$ reviendra sur la nécessité de penser cette spécificité en proposant une théorie dans laquelle il distingue « structure ludique » et « attitude ludique », en plus de différencier de manière analytique le « jeu », le « jouer » et le « jouant ». Néanmoins, il peut être intéressant de se demander s'il est possible d'envisager toute l'organisation sociale à partir d'une base commune. II semble difficile de croire que ce fondement puisse se résumer à l'étiquette du sacré ou même du jeu, car cela dépend précisément de la manière de définir ces termes dans la culture des auteurs. Une manière plus prudente de procéder serait de voir si en partant du cas d'étude qu'est le jeu, ou un jeu, on peut mettre en lumière des mécanismes d'une organisation sociale générale, comme le propose Jacques Henriot (1989: 32) pour qui le jeu « constitue l'un des modèles les plus efficaces, les plus directement opératoires pour l'analyse des situations sociales ». II faudrait alors procéder par comparaison ou contraste avec d'autres activités humaines pour voir les points communs qui pourraient être dégagés de l'analyse, ainsi que les spécificités de chacune. On pourrait essayer de déterminer s'il convient d'appeler « jeu » la relation entre un individu et son environnement dans une activité donnée, ayant une histoire et qui s'organise à l'intérieur de règles, de normes ou de conventions servant à la cadrer. Par exemple, une telle démarche contribuerait aux débats sur des questions d'ordres plus généraux sur l'opposition entre déterminisme et libre arbitre ou sur les rapports entre individus et société.

\footnotetext{
15 Nous remercions Sébastien Genvo pour ses remarques.
} 


\section{Conclusion}

Plusieurs raisons expliquent les choix de composition théorique de Roger Caillois, mais il est indéniable que son intérêt pour l'étude du sacré l'a fait réagir à la lecture d'Homo Ludens (Huizinga, 1938), tant l'ouvrage invite à une discussion sur les liens entre cette notion et celle du jeu telle que proposée par Johan Huizinga. Qu'entre son premier article sur ce thème, en 1946, et son ouvrage de 1958, d'autres raisons soient venues s'y greffer et y donner une tournure particulière (raisons exposées notamment par des ethnologues comme Michel Panoff et Thierry Wendling) ne fait que confirmer ces hypothèses. L'explication d'Olivier Caïra (2007 : 208) selon laquelle « Caillois, comme Huizinga, ne justifie son objet d'étude, peu légitime à l'époque, qu'en le rattachant à d'autres, jugés sérieux », est alors insuffisante. Comme nous l'avons vu, les implications et les enjeux de leurs travaux respectifs sont bien plus importants que cela. Ils sont le reflet d'une vision du monde propre aux deux auteurs, et leurs théories du jeu sont au service de cette vision à partir de laquelle ils essaient chacun de proposer une théorie générale de l'organisation sociale. C'est sur ce fondement que leurs propositions doivent être empruntées et non pas simplement en citant quelques lignes de définition décontextualisées. On comprend alors mieux l'erreur de Jesper Juul (2005 : 197) qui veut proposer un modèle général du jeu (« game ») qui serait valide depuis l'an 3000 av. J.-C., mais qui ne va pas jusqu'à poser la question de l'élargissement possible de ses réflexions à toutes les activités sociales.

L'analyse a permis de montrer qu'il est nécessaire de revenir aux fondements de ce qui constitue la pensée de ces auteurs en discutant les principes qui leur servent à définir des notions comme celles de culture, de civilisation ou leur manière d'appréhender les sociétés dans leur diversité. Par sa polysémie, la notion de jeu nécessite aussi une recontextualisation importante des travaux des chercheurs qui l'emploient. II sera alors possible de voir quels sont les points sur lesquels il est possible de s'en rapprocher. Ainsi convient-il de savoir si l'on s'ancre dans une conception morale et spirituelle de la culture lorsqu'on discute les théories de Johan Huizinga, et de questionner la répartition entre les « sociétés à tohu-bohu » et les « sociétés à comptabilité » lorsqu'on évoque la typologie de Roger Caillois. Ces questionnements permettront d'inscrire les travaux dans des problématiques plus générales en sciences humaines et sociales et permettront de souligner les ruptures entre plusieurs types d'approches. Dans les recherches Johan Huizinga comme dans celles de Roger Caillois, l'idée de jeu renvoie à une certaine vision de l'évolution des sociétés qui s'inscrit dans la filiation de l'école française de sociologie et dans sa volonté de recherche de phénomènes totaux. Mais cette analyse montre aussi qu'une étude de la filiation des concepts, bien que nécessaire, est sans doute insuffisante pour expliquer les influences multiples que constitue tout travail de recherche.

En tant que productions intellectuelles, les recherches sont toujours l'œuvre d'individus en interaction avec d'autres et sont pris dans un contexte historique, social et culturel particulier. De plus, la pensée d'un auteur se construit sur un 
temps parfois long durant lequel elle peut s'affiner ou même prendre des directions différentes en fonction des événements particuliers, liés au monde scientifique aussi bien qu'à des événements extérieurs. Cette réflexion permet alors d'envisager les manières d'interroger les conditions possibles d'une pratique interdisciplinaire en sciences humaines et sociales autour des questions liées à la notion de jeu, en tenant compte des différences fondamentales dans les conceptions du monde et du rôle des individus dans l'organisation de l'espace social étudié.

\section{Références}

Amossy R., 1991, Les idées reçues. Sémiologie du stéréotype, Paris, Nathan.

Andrini S., 1991, « Huizinga et le droit : le procès et le jeu en Italie », Droit et société, 17-|8, pp. 27-4|. Accès : http://www.reds.msh-paris.fr/publications/revue/pdf/ds 17- |8/ ds0 170 | 8-03.pdf. Consulté le 03// I// 3.

Becker H. S., 1999, Propos sur l'art, trad. de l'américain par J. Kempf et al., Paris, Éd. L'Harmattan.

Benveniste É., 1947, « Le jeu comme structure », Deucalion, 2, pp. I6I- 167.

Boas F., 1928, Anthropology and Modern Life, New York, Norton, 1962.

Bogost I., 2007, Persuasive Games. The expressive power of videogames, Cambridge/Londres, MIT Press.

Borgeaud P., 1994, « Le couple sacré/profane. Genèse et fortune d'un concept "opératoire" en histoire des religions », Revue de l'histoire des religions, 4, t. 21 I, pp. 387-4 I8. Accès : http://www.persee.fr/web/revues/home/prescript/article/rhr_0035-I423_1994_ num_2II_4_|385. Consulté le 31/0 I/I2.

Boutaud J.-J., Dufour S., 20 I 3, « Extension du domaine du sacré », Questions de communication, 23, pp. 7-29.

Brougère G., 2005, Jouer/Apprendre, Paris, Éd. Economica.

Caillois R., 1938, L'homme et le mythe, Paris, Gallimard.

— 1939a, « La fête », pp. 645-693, in : Hollier D., 1979, Le collège de Sociologie 1937-1939, Paris, Gallimard, 1995.

- 1939b, L'homme et le sacré, Paris, Gallimard, 1950.

— 1946, « Le ludique et le sacré », Confluences, 10, pp. 66-77.

— 1954, « Illusions à rebours », La Nouvelle Nouvelle Revue française, 24, pp. 1010 - 1024.

— 1955a, « Illusions à rebours (fin) », La Nouvelle Nouvelle Revue française, 25, pp. 58-70.

— 1955b, « À propos de "Diogène couché" », Les Temps modernes, I I I, pp. I 533- I 535.

— 1955c, « Structure et Classification des Jeux », Diogène, 12, pp. 72-88.

— 1957, « Unité du jeu, diversité des jeux 》, Diogène, 19, pp. | 17 - 144.

— 1958a, «Théorie des jeux », Revue de métaphysique et de morale, I, pp. 83- 102.

— 1958b, Les jeux et les hommes. Le masque et le vertige, Paris, Gallimard, 1967. 
— 1967, Jeux et sports, Paris, Gallimard.

— 1970, Cases d'un échiquier, Paris, Gallimard.

- 1974a, Approches de l'imaginaire, Paris, Gallimard.

— 1974b, « Réponse de M. Roger Caillois au discours de M. Claude Lévi-Strauss. Discours prononcé dans la séance publique le jeudi 27 juin 1974 », Académie Française. Accès : http://www.academie-francaise.fr/reponse-au-discours-de-reception-de-claude-levistrauss. Consulté le 04/01/13.

Caïra O., 2007, Jeux de rôle. Les forges de la fiction, Paris, CNRs Éd.

Cuche D., 1996, La notion de culture dans les sciences sociales, Paris, Éd. La Découverte, 2010.

Di Filippo L., François H., Michel A., 20 I2, «Adopter une démarche réflexive : implications et enjeux », pp. 7-28, in : Di Filippo L., François H., Michel A., dirs, La position du doctorant. Trajectoires, engagements, réflexivité, Nancy, PUN-Éditions universitaires de Lorraine.

Di Filippo L., Schmoll P., 2013, « Mise en scène et interrogation du sacré dans les jeux vidéo », Revue des sciences sociales, 49, pp. 64-73.

Durkheim É., 1912, Les formes élémentaires de la vie religieuse, Paris, Presses universitaires de France, 2013.

Ekeland I., I991, Au hasard. La chance, la science et le monde, Paris, Éd. Le Seuil.

Felgine O., 1994, Roger Caillois, Paris, Stock.

Frasca G., 2003, « Simulation versus Narrative : Introduction to Ludology », pp. 22 I-235, in : Perron B., Wolff M. J. P., eds, The Video Game Theory Reader, Londres/New York, Routledge.

Genvo S., 2009, Le jeu à son ère numérique. Comprendre et analyser les jeux vidéo, Paris, Éd. L'Harmattan.

— 2013, «Penser les phénomènes de ludicisation à partir de Jacques Henriot », Sciences du jeu, I. Accès : http://www.sciencesdujeu.org/index.php?id=243. Consulté le 28/09/I3.

Henriot J., 1969, Le jeu, Paris, Presses universitaires de France.

- 1989, Sous couleur de jouer, Paris, J. Corti.

Hollier D., 1979, Le collège de Sociologie 1937-1939, Paris, Gallimard, 1995.

Hubert H., Mauss M., 1899, « Essai sur la nature et la fonction du sacrifice », pp. 193-307, in : Mauss M., Fuvres I. Les fonctions sociales du sacré, Paris, Éd. de Minuit, 1968.

— 1902-1903, « Esquisse d'une théorie générale de la magie », pp. I-141, in : Mauss M., Sociologie et Anthropologie, Paris, Presses universitaires de France, 1983.

— 1906, « Introduction à l'analyse de quelques phénomènes religieux », pp. 3-39, in : Mauss M., Euvres 1. Les fonctions sociales du sacré, Paris, Éd. de Minuit, 1968.

Huizinga J., 1919, L'automne du Moyen Âge, trad. du néerlandais par J. Bastin, Paris, Payot, 2002.

- 1935, Incertitudes. Essai de diagnostic du mal dont souffre notre temps, trad. du néerlandais par J. Roebroek, Paris, Librairie de Médicis, 1939.

- 1938, Homo Ludens. Essai sur la fonction sociale du jeu, trad. du néerlandais par C. Seresia, Paris, Gallimard, 1951.

— 1945, À l'aube de la paix. Étude sur les chances de rétablissement de notre civilisation, trad. du néerlandais par C. Seresia, Amsterdam/Anvers, Éd. Panthéon S. A. 
Isambert F.-A., 1982, Le sens du sacré. Fête et religion populaire, Paris, Éd. de Minuit. Jost F., 2006, « Monde de la télévision et monde de la publicité », Tranel, 44, pp. I8I - 197. Juul J., 2005, Half-Real. Video Games between Real Rules and Fictional Worlds, Cambridge/ Londres, MIT Press.

Leleu-Merviel S., 2010, « De l'infra-conceptuel à des données à horizon de pertinence focalisé », Questions de communication, 18, pp. 171 - 184.

Lévi-Strauss C., 1952, Race et histoire, Paris, Unesco.

— 1955a, « Diogène couché 》, Les Temps modernes, I I0, pp. I I 86- 1220.

— 1955b, « À propos de "Diogène couché” », Les Temps modernes, I I I, pp. I 535- 1536.

- 1962, La pensée sauvage, Paris, Plon.

Massonet S., 1998, Les labyrinthes de l'imaginaire dans l'œuvre de Roger Caillois, Paris, Éd. L'Harmattan.

Mauss M., 1923-1924, « Essai sur le don : Forme et raison de l'échange dans les sociétés archaïques », pp. I43-279, in : Mauss M., Sociologie et Anthropologie, Paris, Presses universitaires de France, 1983.

Mäyrä F., 2008, An Introduction to Game Studies, Londres, Sage.

Otto R., 1917, Le Sacré. L'élément non rationnel dans l'idée du divin et sa relation avec le rationnel, trad. de l'allemand par A. Jundt, Paris, Payot/Éd. Rivages, $200 \mathrm{I}$.

Panoff M., 1993, Les frères ennemis. Roger Caillois et Claude Lévi-Strauss, Paris, Payot/ Éd. Rivages.

Salen K., Zimmerman E., 2003, Rules of Play. Game Design Fundamentals, Cambridge, MIT Press.

Schmoll P., 201 I, « Sciences du jeu : état des lieux et perspectives », Revue des sciences sociales, 45 , pp. $10-17$.

Spengler O., 1918-1922, Le déclin de l'Occident, 2 vols, trad. de l'allemand par M. Tazerout, Paris, Gallimard, 1993.

Tarot C., 2003, « Les lyncheurs et le concombre ou de la définition de la religion, quand même », Revue du MAuss, 22, pp. 270-297. Accès : http://www.cairn.info/revue-du-mauss2003-2-page-270.htm. Consulté le 08/03/I3.

— 2012, «Sur les aléas du vocabulaire du sacré dans les sciences sociales en France au xx siècle », pp. 339-350, in : Souza M. de, Peters-Custot A., Romanacce F.-X., dirs, Le sacré dans tous ses états. Catégories du vocabulaire religieux et sociétés, de l'Antiquité à nos jours, Saint-Étienne, Publications de l'université de Saint-Étienne.

TaylorT. L., 2006, Play between Worlds, Cambridge/Londres, MIT Press.

Todorov T., 1989, Nous et les autres. La réflexion française sur la diversité humaine, Paris, Éd. Le Seuil.

Triclot M., 20I I, Philosophie des jeux vidéo, Paris, Éd. La Découverte.

Wendling T., 2000, « Jeu, illusion et altérité », pp. 25-39, in : Gonseth M.-O., Hainard J., Kaehr R., éds, La grande illusion, Neuchâtel, Musée d'ethnographie.

— 2002, Ethnologie des joueurs d'échecs, Paris, Presses universitaires de France. 
— 2010, « Une joute intellectuelle au détriment du jeu ? Claude Lévi-Strauss vs Roger Caillois (1954-1974)», Ethnologies, I, vol. 32, pp. 29-49.

— à paraître, « Graines de jeux dans les parterres du Collège de sociologie », Anamnèse. Yonnet P., 1999, Travail, loisir. Temps libre et lien social, Paris, Gallimard.

Zimmerman E., 2012, « Jerked Around by the Magic Circle. Clearing the AirTen Years Later, Gamasutra », Gamasutra. Accès : http://www.gamasutra.com/view/feature//35063/ jerked_around_by_the_magic_circle_.php. Consulté le 19/05/20 I3. 